\title{
Depression in Hospital-Employed Nurses
}

By: Susan Letvak, Christopher J. Ruhm, Thomas McCoy

Made available courtesy of Lippincott, Williams \& Wilkins: http://journals.lww.com/cnsjournal/pages/default.aspx

\section{This is a non-final version of an article published in final form in:}

Letvak, S., Ruhm, C. J., McCoy, T. (2012). Depression in Hospital Employed Nurses. Clinical Nurse Specialist, 26(3), 177-82.

\begin{abstract}
:
Depression impacts 9.4\% of the adult population in the United States, and it is known to impact work performance. Nurses with depression are not only likely to suffer themselves, but their illness may have an impact on their coworkers and potentially the quality of care they provide. Thus, the purpose of this study was to determine the prevalence of depression in a random sample of hospital-employed nurses to determine individual and workplace characteristics that are associated with depression. A cross-sectional survey design of 1171 registered nurses was used. Measures included individual characteristics, workplace characteristics, work productivity, and depression (9-item Patient Health Questionnaire). Data analysis demonstrated a depressive symptom rate of $18 \%$. The linear regression model accounted for $60.6 \%$ of the variation in the 9item Patient Health Questionnaire depression scores. Body mass index, job satisfaction, number of health problems, mental well-being, and health-related productivity had significant relationships with depression $(P<.05)$. Hospital-employed nurses have higher rates of depressive symptoms than national norms. Advanced practice nurses can assist with educating nurses on recognizing depression and confidential interventions, including the use of computerized cognitive-based therapy.
\end{abstract}

Keywords: Nursing | Depression | Hospitals | Patient Outcomes

\section{Article:}

The most recent Centers for Disease Control Behavioral Risk Factor Surveillance System ${ }^{1}$ report on depression prevalence found that $9.0 \%$ of US adults met the criteria for depression, including $3.4 \%$ with major depression. Women, and those aged 45 to 64 years, were most likely to be depressed, as were those who were unmarried and unemployed. Direct healthcare workers, including nurses, may be more vulnerable to depression as research has shown that work stress precipitates depression in working women and men. ${ }^{2,3}$ Indeed, healthcare workers were ranked third for depressive episodes of all occupations between 2004 and 2006. ${ }^{4}$ Depression is also costly; in a 3-month period, patients with depression use an average of 4.8 sick days and suffer 11.5 days of reduced productivity. ${ }^{5}$ Almost two-thirds of the estimated $\$ 83$ billion that 
depression cost the United States in the year 2000 resulted from lowered productivity and workplace absenteeism. ${ }^{6}$

The greatest concern to the nursing profession is that depressed workers often exhibit low mood, have difficulty with concentration, and are accident prone; they are also significantly more limited in their ability to perform mental or interpersonal tasks, have worse time management skills, and have lower total work output than nondepressed workers. ${ }^{7-9}$ Thus, not only are hospital nurses with depression likely to suffer themselves, but also their illness is likely to impact their coworkers and potentially the quality of care they provide. The purpose of this study was to determine the prevalence of depression in a random sample of hospital nurses licensed in North Carolina and to determine individual and workplace characteristics that are associated with depression. Advanced practice nurses are in a unique position not only to recognize depression in nurses, but also to offer treatment options that will be confidential and accessible to nurses.

\section{LITERATURE REVIEW}

There is a vast body of literature on depression; thus, this review will focus on research conducted on depression in healthcare workers, most of which has taken place outside the United States. Peterson and colleagues ${ }^{10}$ surveyed all Swedish healthcare workers to look at how burnout impacts physical and mental health. Registered nurses made up 33.7\% ( $\mathrm{N}=1252)$ of the respondents. Burnout was defined as a syndrome of work-related negative experiences, including

feelings of exhaustion and disengagement from work, ${ }^{10(\mathrm{p} 86)}$ and was measured by the Oldenburg Burnout Inventory. Depression was measured by the Hospital Anxiety and Depression Scale, which consists of 7 items for depression and 7 items for anxiety.

The cutoff scores for mild depression are 8 to 10; moderate depression, 11 to 14; and severe depression, 15 to 21 . Mild depression was found in $18.1 \%$ of the group with high burnout scores, whereas only $1.6 \%$ were depressed in the group with low burnout scores. Moderate to severe depression was found in $10.4 \%$ of group with high burnout scores, and only $0.2 \%$ in the group with low burnout scores. These findings could point to depression leading to burnout as well as burnout creating depression. Virtanen and colleagues ${ }^{11}$ conducted a study of physicians and nurses in 16 hospitals in Finland to determine the relationship between bed occupancy rates and antidepressant treatment. Bed occupancy rates were considered to be a measure of nursing workload. In the sample of 6669 nurses, they found that exposure over 6 months to an average bed occupancy rate over $10 \%$ in excess of the recommended limit was associated with an increasing likelihood of antidepressant use, which followed a dose-response pattern. Thus, high workloads may be associated with higher depression rates. 
Jolivet and colleagues ${ }^{12}$ surveyed nurses and nursing assistants working in French teaching hospitals to determine the association between organizational work environment and depressive symptoms. The study sample was made up of 1927 registered nurses (RNs) and 1389 nursing assistants. The average age of the nurses was 35.8 years, and that of the assistants was 40.5 years. Depressive symptoms were measured using the Center for Epidemiologic Studies Depression Scale. Scores of 15 to 21 indicated mild to moderate depression, and greater than 21 indicates the possibility of major depression. Average depression scores were higher for nursing assistants (mean of 12.8) than RNs (mean of 10.9). Poor relations between workers and low levels of communication were found to be associated with higher depressive symptom scores.

Lin et $\mathrm{al}^{13}$ surveyed 154 nurses employed in a psychiatric hospital in Taiwan to determine the association between job stress, coping, social support, and depression. Using the Beck Depression Inventory II, the researchers reported mild depression in 12.8\%, moderate depression in $7.8 \%$, and severe depression in $7.1 \%$ of the respondents. Job stress and affective-oriented coping were positively correlated with depression scores. Social support was not significantly correlated with depression, but did moderate the relationship between job stress and depression.

Gartner and colleagues ${ }^{14}$ conducted a systematic review of the literature on the impact of common mental disorders on the work functioning of nurses and allied health professionals. There were 16 studies that included nurses in the sample. The studies covered fatigue, stress, burnout, addiction, and anxiety, with only one specifically addressing depression, which was not measured but self-reported. The researchers concluded that evidence exists between common mental disorders in nurses and higher rates of general and medication errors, and decreased patient safety and patient satisfaction rates. The researchers also pointed out that although a positive relationship exists between mental disorders and patient outcomes, all yielded data were association coefficients; thus, conclusions about causality must be drawn with caution. Poor work conditions can impair the mental health of employees, and mental health problems can negatively impact work outcomes.

A study was conducted on posttraumatic stress disorder (PTSD) and depression prevalence in US healthcare workers returning from Iraq and Afghanistan. Grieger et $\mathrm{al}^{15}$ surveyed 102 returning healthcare professionals, with nurses making up only 5 of the respondents. Depression was found in 5\% of the sample, measured using the 9-item Patient Health Questionnaire (PHQ-9). Specific demographic information on which healthcare providers had depression was not reported.

Finally, 2 studies were found that specifically measured depression in hospital-employed nurses in the United States. Mealer and colleagues ${ }^{16}$ surveyed intensive care and general medicalsurgical nurses working in Georgia hospitals to determine the prevalence of depression and PTSD. Depression was measured utilizing the Hospital Anxiety and Depression Scale. The researchers found that intensive care nurses had higher PTSD rates than medical-surgical nurses. They also found that $31 \%$ of intensive care nurses and $27 \%$ of medical-surgical nurses had possible symptoms of depression. The researchers pointed out that these rates were higher than 
healthcare managers' rates of depression, and more attention must be paid to the well-being of staff nurses. Welsh ${ }^{17}$ conducted a study of 150 nurses employed on medical-surgical units. The average age of respondents was 38 (SD, 11) years, and they had worked an average of 10 (SD, 9.3) years in nursing. Utilizing the Center for Epidemiologic Studies Depression Scale to measure depression, the estimated prevalence rate was $35 \%$ for mild to moderate depression and $21 \%$ for major depression. Depressive symptoms were correlated with having somatic complaints, major life events, and occupational stress.

The review of the literature demonstrates that nurses may have high rates of depression that may have an impact on quality of care. Although studies have been conducted on depression in nurses, few looked at specific variables that are associated with an increased risk for depression. Thus, more research is needed on specific variables that may contribute to depression in hospitalemployed nurses and the effect on patient care quality and safety.

\section{METHOD}

A cross-sectional survey of 2500 randomly selected RNs licensed in North Carolina and employed in hospital settings was utilized. The North Carolina Board of Nursing is able to provide computer randomized, variable-specific, mailing lists of nurses for approved research studies. A random list of nurses employed in hospital settings was requested. In addition, the introductory letter that accompanied the survey stated that only nurses who work directly with patients are being asked to complete the survey. Institutional review board approval was first received. Mailed surveys were used instead of distributing surveys directly to nurses because of the personal nature of survey questions and to ensure anonymity. Dillman's ${ }^{18}$ strategies for enhancing response rates to mailed surveys were followed. Three weeks after the initial survey mailing, a follow-up postcard was sent, which included contact information if the original survey was misplaced and a new one needed to be sent (only 3 were requested). A dollar bill was provided to encourage participation. Despite the North Carolina Board of Nursing keeping up-todate addresses and information on licensed RNs, 57 envelopes were returned as undeliverable, 12 respondents stated they were no longer working in nursing, and 14 respondents indicated they were retired but retained their licenses. A total of 1171 complete surveys were returned and used for analysis ( $47 \%$ response rate).

\section{Measures}

The survey instrument was developed from a review of the nursing workforce literature. Individual characteristics included age, gender, ethnicity/race, marital status, height and weight (converted to a body mass index [BMI] score), years worked as an RN, and highest degree earned. Questions were asked on smoking and drinking of alcohol, as well as on physical and 
mental well-being (both on a 0- to 10-point numeric rating scale), specific health problems, and possible degree of musculoskeletal pain (on a 0- to 10-point numeric rating scale) the RNs experienced on any given day. Workplace characteristics included primary shift worked, department, employment status (full, part, or flex time), hours worked per day and week, salary, job satisfaction (on a 0- to 5-point numeric rating scale), quality of care provided (on a 4-point numeric rating scale of poor to excellent), and how their health impacts their productivity (on a 0- to 10-point scale). Depression was measured by the PHQ-9, a 9-item self-report depression tool developed for use in primary care. ${ }^{19}$ The 9 items come directly from theDiagnostic and Statistical Manual of Mental Disorders, Fourth Edition signs and symptoms of major depression. The PHQ-9 has fewer items than other depression measures, yet has comparable sensitivity and specificity, with a Cronbach [alpha] of .89. ${ }^{19}$ Scores range from 0 to 27, with scores of 0 to 4 indicating no depressive symptoms, 5 to 9 indicating minimal symptoms, scores of 10 to 14 indicating mild to moderate depression, scores of 15 to 19 indicating moderately severe depression, and scores greater than 20 indicating severe depression. ${ }^{19}$ The PHQ-9 was also chosen over other depression instruments because it has recently been used to assess the levels of depression in healthcare worker. ${ }^{15}$

\section{Data Analysis}

Total depression score (TDS) from the PHQ-9 was initially analyzed using descriptive statistics and graphical displays. Multivariable robust linear regression ${ }^{20}$ was performed to model the relationship between TDS and potential predictors after violation of linear regression assumptions was found. A 2-sided $\mathrm{P}<.05$ was considered statistically significant.

\section{FINDINGS}

Ninety-one percent of participants were female. The average age of participants was $44.7 \pm 11.2$ years (range, 21-72 years). Table 1 presents the sample demographics. The majority (79\%) reported having at least 1 health problem that impacted their work productivity. The average TDS was $5.3 \pm 5.0$, with a median score of 4.0 (range, 0-26). Forty-four percent had a TDS score of 0 to 4, 25\% scored 5 to 9, 12\% scored 10 to 14, 4\% scored 15 to 19, and 2\% scored 20 to 27. Eleven percent had a score of 0 , and $18 \%$ scored 10 or higher. In addition, the most reported health problems in these nurses were allergies (21.1\%), musculoskeletal pain (19.1\%), hypertension (17.9\%), headaches (16\%), and joint pain (16\%).

Table 1. Sample Demographics $(\mathrm{N}=1171)$ 


\begin{tabular}{|l|c|}
\hline Variable & Mean (SD) or $\%$ \\
\hline Age, $y$ & $44.7(11.2)$ \\
\hline Gender & \\
\hline Female & $91.6 \%$ \\
\hline Male & $8.4 \%$ \\
\hline Race/ethnicity & \\
\hline Asian/Pacific Islander & $2.6 \%$ \\
\hline Black/African American & $7.9 \%$ \\
\hline Hispanic/Latino & $0.9 \%$ \\
\hline White/Non-Hispanic & $85.2 \%$ \\
\hline American Indian & $0.5 \%$ \\
\hline Other/mixed & $1.5 \%$ \\
\hline Marital status & \\
\hline Never married & $9.3 \%$ \\
\hline Married & $72.9 \%$ \\
\hline Divorced/separated/widowed & $16.1 \%$ \\
\hline Living with partner & $0 \%$ \\
\hline Highest degree & \\
\hline Diploma & $9.3 \%$ \\
\hline Associate & $0.1 \%$ \\
\hline Bachelor's & $1.0 \%$ \\
\hline Master's & $27.3(5.97)$ \\
\hline DNP/PhD & $10.9(3.63)$ \\
\hline Other & $36.0(9.84)$ \\
\hline Body mass index, kg/m ${ }^{2}$ & $(8.97)$ \\
\hline Employment & \\
\hline Hours worked per day & \\
\hline Hours worked per week & \\
\hline Hourly salary & \\
\hline
\end{tabular}

Several characteristics were significantly associated with TDS and were considered for multivariable linear regression modeling. Table 2 presents the results of the multivariable linear regression modeling. The linear regression model accounted for $60.6 \%$ of the variation in PHQ-9 depression scores, but also indicated significant heteroscedasticity $(\mathrm{P}<.001)$. Thus, results from robust linear regression are subsequently presented here. 
Table 2. Multivariable Robust Linear Regression of the 9-Item Patient Health Questionnaire Total Depression Scores

\begin{tabular}{|c|c|c|c|}
\hline Covariate & $b$ & $\begin{array}{l}95 \% \text { Confidence } \\
\text { Interval for } b\end{array}$ & $P$ \\
\hline Intercept & 14.98 & 13.82 to 16.15 & $<.001$ \\
\hline BMI group ${ }^{a}$ & & & $d f=2, .006$ \\
\hline $\begin{array}{l}\text { Underweight/ } \\
\text { normal }\end{array}$ & - & - & - \\
\hline Overweight & 0.39 & -0.00 to 0.78 & .050 \\
\hline Obese & 1.09 & 0.66 to 1.52 & $<.001$ \\
\hline Satisfaction & -0.51 & -0.69 to -0.33 & $<.001$ \\
\hline Health problems & 0.40 & 0.29 to 0.52 & $<.001$ \\
\hline Mental well-being & -1.26 & -1.37 to -1.16 & $<.001$ \\
\hline Productivity & 0.50 & 0.40 to 0.60 & $<.001$ \\
\hline \multicolumn{4}{|c|}{$\begin{array}{l}\text { Abbreviations: } B M I \text {, body mass index; } R C \text {, reference category, } \\
\text { 'Underweight/normal: } B M I \leq 25 \mathrm{~kg} / \mathrm{m}^{2} \text {, overweight: } 25 \mathrm{~kg} / \mathrm{m}^{2}<B M l<30 \mathrm{~kg} / \mathrm{m}^{2} \text {, } \\
\text { obese: } B M I \geq 30 \mathrm{~kg} / \mathrm{m}^{2} \text {. }\end{array}$} \\
\hline
\end{tabular}

The final multivariable linear regression model indicated that $\mathrm{BMI}$ group ( $\mathrm{df}=2, \mathrm{P}=.006$ ), job satisfaction ( $\mathrm{P}<.001)$, number of health problems $(\mathrm{P}<.001)$, mental well-being $(\mathrm{P}<.001)$, and health-related productivity $(\mathrm{P}<.001$ ) had significant relationships with TDS. More specifically, those participants who were overweight had scores of 0.39 more points on average compared with underweight/normal participants $(\mathrm{P}=.050)$, adjusting for the other predictors in the model. Obese participants scored 1.09 points higher on average compared with underweight/normal participants in the adjusted modeling $(\mathrm{P}<.001)$. More satisfied participants were associated with lower depression scores $(\mathrm{b}=-0.51, \mathrm{P}<.001)$. Those with a greater number of health problems were associated with higher depression scores $(\mathrm{b}=0.40, \mathrm{P}<.001)$. Participants with higher mental health scores were associated with lower depression scores $(b=-1.26, \mathrm{P}<.001)$. Finally, those with lower productivity scores (health problems impacted their productivity) were associated with higher TDSs $(b=0.50, \mathrm{P}<.001)$ in the adjusted modeling.

\section{DISCUSSION}


Although most are aware of high depression rates in the United States, few consider that nurses themselves may also experience depressive symptoms, especially at a rate twice as high as the general public. Langlieb and DePaulo ${ }^{21}$ state that, like cancer and cardiovascular disease, there are so many risk factors for depression that each affected individual may have a unique set of factors contributing to his/her depression. However, in this study, the specific individual variables that were associated with depression were BMI, job satisfaction, number of health problems, mental well-being, and health-related job productivity.

In this study, 32\% of participants were overweight, and $24 \%$ were obese. These findings are not surprising because $29 \%$ of adults in North Carolina are considered to be obese, ${ }^{22}$ and a study of hospital nurses found that $37 \%$ were overweight and $28 \%$ were obese. ${ }^{23}$ However, nurses with higher BMIs were more likely to be depressed in this study. Although an association exists between BMI and depression, it cannot be assumed that higher BMI directly predicts depression in nurses. Research points to the fact that depression can cause an increased appetite, leading to weight gain, and people who are overweight or obese internalize negative attitudes, which can then lead to depressive symptoms. ${ }^{24}$ In mainstream US society, people individually and collectively react to being "fat" as a stigma, where continued negative evaluation leads to a discounting or tainting of the individual's social identity. ${ }^{25}$ A plethora of research has documented the stigma attached to being obese, and weight-based stereotyping often portrays those who are overweight as lazy, weak-willed, unsuccessful, unintelligent, lacking in selfdiscipline, and being noncompliant. ${ }^{26}$ This stigmatization has been well documented as a significant risk factor for depression, even when controlling for variables including age, gender, obesity onset, and BMI, suggesting that negative psychological outcomes are more likely linked to stigmatization than excess body weight itself. It is important to note the negative impact of obesity on an individual's health and work productivity, and successful weight loss is inherently complex and difficult.

In this study, those with lower job satisfaction were more likely to be depressed. Similar to the association between BMI and depression, a cause-and-effect relationship cannot be assumed that having low job satisfaction leads to depression in nurses. Whereas 1 study of 356 nurses who worked in German hospitals found that poor working conditions led a decrease in physical and mental health symptoms in nurses, ${ }^{27}$ large population studies support that while low job satisfaction may contribute to depression or an increase in depressive symptoms, depressed workers are also more likely to have lower job satisfaction. ${ }^{28} \mathrm{~A}$ vast amount of research has been conducted on job satisfaction in nursing, with organizational factors having the greatest impact, followed by economic and personal factors. ${ }^{29}$ Nurses and nurse leaders must strive for improved work conditions that ensure positive mental health of nurses.

Finally, having health problems, lower-rated mental well-being, and lower health-related job productivity were related to depression in these nurses. Research documents that nurses' physical activities, smoking, and dietary patterns are no healthier than the general population, which lead to poor health. ${ }^{30}$ Although it is not surprising that depression coexists with common medical 
problems, a synthesis of the literature found that chronic medical conditions along with depression compound workforce impairment. ${ }^{31}$ This study's findings are also consistent with studies of the general workforce ${ }^{8,9}$ and healthcare workers, ${ }^{14}$ which found relationships between depression and negative job performance. Until nurse managers, hospital administrators, and policy makers seriously address the multitude of workplace concerns in hospitals today, nurses will continue to suffer the ill effects from unhealthy work environments.

Because depression in hospital nurses can be assumed to impact not only the nurse and his/her colleagues, but also potentially his/her quality of care, it is imperative that more attention is placed on depression screening and providing early treatment. Advanced practice nurses can educate the staff nurses they work with on the high prevalence of depression in nurses. Because of the stigma attached to mental illness, nurses, like the general population, may be reluctant to get screening and treatment. Population studies demonstrate that only $29 \%$ of persons with depressive symptoms report contacting a mental health professional in the past year, and among those with severe depression, only 39\% reported contact. ${ }^{31}$ Few hospitals provide free yearly health screenings for nurses, and even if screening was provided, nurses may be reluctant to honestly answer depression screening questions to their employer. Thus, a confidential and costeffective means of providing screening would be to offer Web-based screening to all nurses. Recent research has documented the effectiveness of Web-based screening in the working population. ${ }^{32}$ Nurses who screen positive for depressive symptoms can then be provided with a list of available resources, including employee assistance support, local mental health counselors, psychiatric care services, and healthy lifestyle resources in a confidential manner.

Because those with diagnosed depression are often reluctant to seek treatment, clinical nurse specialists can inform nurses about available Web-based cognitive-based therapy (CBT). It is well recognized that $\mathrm{CBT}$ is highly effective for treatment and prevention of depression, with or without medication therapy. Computerized CBT (CCBT) removes barriers to receiving CBT, which include fear of seeking treatment because of the stigma attached to mental illness, time constraints, and cost. ${ }^{33,34}$ Research in general population studies shows that CCBT is as effective as face-to-face CBT, is highly received by users, and offers tremendous potential for treating people who may be resistant to seeking treatment for depression. ${ }^{35-37}$

Stuhlmiller and Tolchard 38 provide an overview of available CCBT programs that include computer-only-based programs such as Mindstreet: Good Days Ahead: The Multimedia Program for Depression (www.mindstreet.com) and free Web-based programs, the most popular being MoodGym (http://www.moodgym.anu.edu.au) and Ecouch (http://ecouch.anu.edu.au), which were developed in Australia but offered to users worldwide. In the United States, Kaiser Permanente offers HealthMedia-Overcoming Depression for free to their members. Nurses who do not relate well to computers should be encouraged to receive face-to-face counseling. 
Although nurses with depression can always seek assistance from their employee assistance programs, other strategies for assisting nurses with depression include increasing awareness and sensitivity toward depression in both staff nurses and managers, ensuring policies are in place that support good mental health and treatment for those with health problems, providing supportive work environments, and making reasonable job accommodations for nurses whose depression is impacting their work performance. Importantly, clinical nurse specialists and all nurses must seek to remove the stigma attached to depression and mental illness, allowing those with depression to openly seek screening and treatment.

\section{Limitations}

Limitations of this study include the use of a cross-sectional design, a 1-state sample, and selfreported measures. However, the demographics of the sample were similar to the national workforce, and self-reported measures allowed for anonymity. Future research is clearly warranted on depression in the nursing workforce, especially on ways of reducing the prevalence of depression and on effective treatment interventions.

\section{CONCLUSION}

This study documents that depressive symptoms affect enough nurses to warrant concern and intervention. In addition, high-stress environments are likely to lead to more health problems in nurses, including mental health problems, which are less likely to be disclosed than physical problems. The increasing focus on quality and error-free care requires a healthy workforce. Clinical nurse specialists can provide essential education to nurses on the high prevalence of depression and confidential treatment options. It is imperative that more attention be given to screening and early intervention of depression to ensure a satisfied, productive, and high-quality workforce.

\section{ACKNOWLEDGMENT}

The authors thank Sat Gupta, PhD, who assisted with the statistics for the primary grant.

\section{References}

1. Centers for Disease Control and Prevention (CDC). Current depression among adults- United States, 2006 and 2008. MMWR Morb Mortal Wkly Rep. 2010; 59 (38): 1229-1259. 
2. Blackmore ER, Stansfeld SA, Weller I, Munce S, Zagorski BM, Stewart DE. Major depressive episodes and work stress: results from a national population survey. Am J Public Health. 2007; 97 (11): 2088-2093.

3. Melchior M, Caspl A, Milne BJ, Danese A, Poulton R, Moffitt TE. Work stress precipitates depression and anxiety in young, working women and men. Psychol Med. 2007; 37 (8): 11191129.

4. OAS. Results From the 2006 National Survey on Drug Use and Health: National Findings. 2007. Rockville, MD: Substance Abuse and Mental Health Services Administration. DHHS Publication SMA 07-4294, NSDUH Series H-32.

5. Naydeck BL, Pearson JA, Ozminkowski RJ, Day BT, Goetzel RZ. The impact of the Highmark employee wellness programs on 4-year health care costs. J Occup Environ Med. 2008; 50 (2): 146-156.

6. Greenberg PE, Kessler RC, Birnbaum HG, et al.. The economic burden of depression in the United States: how did it change between 1990 and 2000. J Clin Psychiatry. 2003; 64 (12): 1465-1475.

7. Jacob IG. Depression’s impact on safety. Occup Health Saf. 2006; 75 (10): 32, 4, 8 passim.

8. Lerner D, Henke RM. What does research tell us about depression, job performance, and work productivity? J Occup Environ Med. 2008; 50 (4): 401-410.

9. Wang JL, Schmitz N, Smailes E, Sareen J, Patten S. Workplace characteristics, depression, and health-related presenteeism in a general population sample. J Occup Environ Med. 2010; 52 (8): 836-842.

10. Peterson U, Demerouti E, Bergstrom G, Samuelsson M, Ake MA, Nygren A. Burnout and physical and mental health among Swedish healthcare workers. J Adv Nurs. 2008; 62 (1): 84-95.

11. Virtanen M, Pentti J, Vahtera J, et al.. Overcrowding in hospital wards as a predictor of antidepressant treatment among hospital staff. Am J Psychiatry. 2008; 165 (11): 1482-1486.

12. Jolivet A, Caroly S, Ehlinger V, et al.. Linking hospital workers' organisational work environment to depressive symptoms: a mediating effect of effort-reward imbalance? The ORSOSA study. Soc Sci Med. 2010; 71 (3): 534-540.

13. Lin HS, Probst JC, Hsu YC. Depression among female psychiatric nurses in southern Taiwan: main and moderating effects of job stress, coping behaviour and social support. J Clin Nurs. 2010; 19 (15-16): 2342-2354. 
14. Gartner FR, Nieuwenhuijsen K, van Dijk FJ, Sluiter JK. The impact of common mental disorders on the work functioning of nurses and allied health professionals: a systematic review. Int J Nurs Studies. 2010; 47: 1047-1061.

15. Grieger TA, Kolkow TT, Spira JL, Morse JS. Post-traumatic stress disorder and depression in health care providers returning from deployment to Iraq and Afghanistan. Mil Med. 2007; 172 (5): 451-455.

16. Mealer ML, Shelton A, Berg B, Rothbaum B, Moss M. Increased prevalence of posttraumatic stress disorder symptoms in critical care nurses. Am J Respir Crit Care Med. 2007; 175: 693-697.

17. Welsh D. Predictors of depressive symptoms in female medical-surgical hospital nurses. Issues Ment Health Nurs. 2009; 30 (5): 320-326.

18. Dillman D. Mail and Telephone Surveys: The Total Design Method. New York: John Wiley and Sons; 1978.

19. Kroenke K, Spitzer RL, Williams JB. The PHQ-9: validity of a brief depression severity measure. J Gen Intern Med. 2001; 16 (9): 606-613.

20. Yohai VJ. High breakdown-point and high-efficiency robust estimates for regression. Ann Stat. 1987; 15 (2): 642-656.

21. Langlieb AM, DePaulo JR Jr. Etiology of depression and implications on work environment. J Occup Environ Med. 2008; 50 (4): 391-395.

22. CDC. US Obesity Trends: trends by state 1985-2008.

2011.http:/www.cdc.gov/obesity/data/trends.html. Accessed November 29, 2011.

23. Zapka JM, Lemons SC, Magner RP, Hale J. Lifestyle behaviours and weight among hospitalbased nurses. J Nurs Manag. 2009; 17: 853-860.

24. Needham BL, Epel ES, Adler NE, Kiefe C. Trajectories of change in obesity and symptoms of depression: the CARDIA Study. Am J Public Health. 2010; 100 (6): 1040-1046.

25. Brewis AA, Hruschka DJ, Wutich A. Vulnerability to fat-stigma in women’s everyday relationships. Soc Sci Med. 2011; 73 (4): 491-497.

26. Puhl RM, Heuer CA. Obesity stigma: important considerations for public health. Am J Public Health. 2010; 100 (6): 1019-1028. 
27. Schulz M, Damkroger A, Voltmer E, et al.. Work-related behaviour and experience pattern in nurses: impact on physical and mental health. J Psychiatr Ment Health Nurs. 2011; 18 (5): 411417.

28. McIntyre RS, Liauw S, Taylor VH. Depression in the workforce: the intermediary effect of medical comorbidity. J Affect Disord. 2011; 128: S29-S36.

29. Djukic M, Kovner C, Budin WC, Norman R. Physical work environment: testing an expanded model of job satisfaction in a sample of registered nurses. Nurs Res. 2010; 59 (6): 441-451. HTML Full Text

30. Hensel D. Relationships among nurses professional self-concept, health, and lifestyles. West J Nurs Res. 2011; 33(1): 45-62.

31. Pratt LA, Brody DJ. Depression in the United States household population, 2005-2006. NCHS Data Brief. 2008 (7): 1-8.

32. Harvey SB, Glozier N, Henderson M, et al.. Depression and work performance: an ecological study using Web-based screening. Occup Med. 2011; 61 (3): 209-211.

33. Christensen H, Griffiths KM, Jorm AF. Delivering interventions for depression by using the internet: randomised controlled trial. BMJ. 2004; 328 (7434): 265

34. Titov N. Status of computerized cognitive behavioural therapy for adults. Aust N Z J Psychiatry. 2007; 41 (2): 95-114.

35. Christensen H, Griffiths KM, Mackinnon AJ, Brittliffe K. Online randomized controlled trial of brief and full cognitive behaviour therapy for depression. Psychol Med. 2006; 36 (12): 17371746.

36. de Graf LE, Huibers MJH, Riper H, Gerhards SAH, Arntz A. Use and acceptability of unsupported online computerized cognitive behavioral therapy for depression and associations with clinical outcome. J Affect Disord. 2009; 116 (3): 227-231.

37. Spek V, Nyklicek I, Smits N, et al.. Internet-based cognitive behavioural therapy for subthreshold depression in people over 50 years old: a randomized controlled clinical trial. Psychol Med. 2007; 37 (12): 1797-1806.

38. Stuhlmiller C, Tolchard B. Computer-assisted CBT for depression and anxiety: increasing accessibility to evidence-based mental health treatment. J Psychosoc Nur Ment Health Serv. 2009; 47 (7): 32-39. 